\title{
Oraland Maxillofacial Lesions in an Elderly Population in Shiraz, Iran
}

\author{
Soheil Pardis ${ }^{1}$; Mohammad Mehdi Taheri ${ }^{2}$; Mohammad Mehdi Fani ${ }^{3, *}$ \\ ${ }^{1}$ Department of Oral Pathology, School of Dentistry, Shiraz University of Medical Sciences, Shiraz, IR Iran \\ Department of Oral Pathology, School of Dentistry, Shiraz University of Medical Sci
${ }^{2}$ Student Research Committee, Shiraz University of Medical Sciences, Shiraz, IR Iran \\ ${ }^{3}$ Student Research Committee, Shiraz University of Medical Sciences, Shiraz, IR Iran \\ ${ }^{*}$ Corresponding author: Mohammad Mehdi Fani, Department of Oral Medicine, School of Dentistry, Shiraz University of Medical Sciences, Shiraz, IR Iran. Tel: +98-9171118583, Fax: \\ +98-7116280807, E-mail: fanim@sums.ac.ir \\ Received: June 6, 2014; Revised: June 14, 2014; Accepted: June 20, 2014
}

\begin{abstract}
Background: Aging causes many changes in human physiology, increasing the risk of pathologic conditions in elderly populations. Different studies have shown higher frequency of oral and maxillofacial lesions in older people. Knowing the prevalence and distribution of these lesions can help dentists in screening these patients.

Objectives: This study aimed to evaluate the frequency and distribution of oral pathologic lesions among patients referred to Oral Pathology Department of Shiraz Dental School.

Patients and Methods: By referring to archives of Oral Pathology Department of Shiraz University of Medical Sciences, the histopathological reports of all 231 patients aged 60 years or over were reviewed. The data were described and analyzed using SPSS software. Chi-square test was performed and a P value less than 0.05 was considered significant.

Results: The most prevalent lesion was oral lichen planus (21.6\%), followed by inflammatory fibrous hyperplasia (15.8\%) and squamous cell carcinoma (7.6\%). There was a statistically significant difference between men and women in the occurrence of odontogenic cysts and dermatologic diseases. $(\mathrm{P}=0.018$ and 0.002 , respectively;chi-square $=5.63$ and 9.47, respectively). Moreover, non-neoplastic lesions were the most prevalent group of lesions in this study.

Conclusions: High frequency of life-threatening oral conditions among elderly populations makes it essential for dentists to pay special attention to the most frequent lesions and help enhance the life quality of elderlies by early diagnosis and management of these diseases.

Keywords:Pathology; Pathology, Oral; Elderly
\end{abstract}

\section{Background}

Aging can cause physiological changes in oral cavity. During the aging process, oral mucosa loses much of its efficacy, getting predisposed to oral pathoses (1). At the time, the number of elderlies (above 60 years old as defined by World Health Organization) has exceeded five million $(2,3)$. Hence, it is of crucial importance to manage oral conditions of the elderlies. There have been numerous studies worldwide evaluating the frequency and distribution of oral lesions in elderly patients. Scott et al. for example analyzed 4000 biopsies and found that $20 \%$ of them were related to patients over 60 . They also reported a high incidence of premalignant lesions and denturerelated hyperplasia among these patients (3). Correa et al. reported a higher incidence of epithelial malignant and premalignant conditions, autoimmune diseases, and salivary gland tumors in an elderly population in Brazil. In their study, inflammatory fibrous hyperplasia, squamous cell carcinoma (SCC) and fibroma were the most common lesions (4). A similar survey in Finland revealed a higher incidence of premalignant lesions and radicular cysts in elderlies (5).

Cueto et al. studied 126 patients over the age of 60 and reported that $67.5 \%$ of them had oral mucosal conditions.
The most frequent lesion was denture-induced stomatitis. They also found a statistically significant relationship between the use of denture and oral candidiasis. Moreover, the use of drugs and denture was observed to contribute to increasing the prevalence of oral lesions (6). In a recent study, Carvalho et al. studied 534 biopsies and reported a higher prevalence of pathologic lesions in females. They also found that non-neoplastic lesions were more common than benign tumors, as well as from malignant and premalignant conditions (7).

There have been studies in Iran evaluating the incidence of oral conditions clinically, not histopathologically. Mozafari et al. studied all the nursing homes in Mashhad, Iran. The most common lesions in their study were fissured tongue, atrophic glossitis, sublingual varicosity and xerostomia (8). Rabiei et al. examined 216 elderly people and reported an incidence of $86.1 \%$ for oral conditions. The most common lesions in their study were dry mouth, fissured tongue, and atrophy of tongue (9).

\section{Objectives}

As aging causes many socioeconomic and physical limitations for elderly patients and may restrict their access to appropriate treatments and due to the importance of

Copyright (C) 2014, Hamadan University of Medical Sciences. This is an open-access article distributed under the terms of the Creative Commons Attribution-NonCommercial 4.0 International License (http://creativecommons.org/licenses/by-nc/4.0/) which permits copy and redistribute the material just in noncommercial usages, provided the original work is properly cited. 
Pardis S et al.

early detection and treatment of malignant lesions, we performed this study. Hopefully the findings of the study will help dentists to make more accurate differential diagnoses.

\section{Patients and Methods}

This was a cross-sectional study performed in Shiraz University of Medical Sciences, Iran, in 2013. Sampling was performed by census and by referring to archives of the Oral Pathology Department of Dentistry School, Shiraz University of Medical Sciences, from 2002 to 2011. The study comprised 231 participants over 60 years oldwith at least one pathologic condition. The participants' sex, age, associated lesion and diagnosis, and location of the lesion were recorded. Reports with nondefinitive diagnoses and the ones requiring further biopsy were excluded from the study. Moreover, participants whose ages were not mentioned were not entered to the study. Lesions were classified into eight groups according to the textbook of oral and maxillofacial pathology (10). After collecting the data, the researchers tabulated and described them using SPSS software (statistical package for the social sciences for windows 17.0; SPSS Inc., Chicago, IL, USA). Chisquare test was performed to evaluate the gender difference in the prevalence of lesions. P value less than 0.05 was considered significant. The study also reported common locations for different kinds of lesions.

Ethical issues were considered during all the study stages. Only the research team had access to the archives and no private information of the patients were mentioned anywhere in the study.

\section{Results}

From 1304 biopsies available at the archives of the Oral Pathology Department, 231 biopsies (17.7\%) were related to patients with 60 years of age or older. A total of 208 participants were included in this study and 23 were excluded. The mean age of the included patients was $68 \pm 4.2$. The prevalence of lesions according to the patients'age is shown in Table 1. Most of the lesions were related to patients from 60 to 69 years old. Females comprised 54.8\% of the participants, the percentage of which was slightly higher than the male participants (45.2\%). The most common lesion was oral lichen planus (OLP) $(21.6 \%, n=45)$, followed by inflammatory fibrous hyperplasia $(15.8 \%, \mathrm{n}=$ 33 ) and SCC $(7.6 \%, \mathrm{n}=16)$.

The mean age of patients was $66.9 \pm 2.6$ for OLP, $67.1 \pm$ 1.7 for inflammatory fibrous hyperplasia, and $71.7 \pm 2.2$ for squamous cell carcinoma. SCC was more prevalent in men $(62.5 \%)$. In contrast, $75 \%$ of patients with OLP were female. Inflammatory fibrous hyperplasia was slightly more prevalent among females than in males (51.5\% compared to $48.5 \%$, respectively). Owing to the diversity of lesions including soft tissue and hard tissue diseases, we proposed two types of classifications to include all the lesions; the first, as shown in Table 2, considered the origin of the lesions.

Table 1. Frequency of Lesions in Different Age Groups

\begin{tabular}{lc}
\hline Age Range, $\mathbf{y}$ & Lesions, \% \\
\hline 60-69 & 61.1 \\
\hline 70-79 & 32.6 \\
80 And older & 6.3 \\
\hline
\end{tabular}

Table 2. Frequency of Different Groups of Lesions in Elderly Patients Based on Their Origins ${ }^{\mathrm{a}}$

\begin{tabular}{|c|c|c|c|c|}
\hline Type of Lesion & Male & Female & Total & lesions \\
\hline Soft tissue tumors & $37(17.8)$ & $35(16.8)$ & $72(34.6)$ & $\begin{array}{c}\text { Peripheral giant cell granuloma, Irritation fibroma, pyogenic granuloma, epulis } \\
\text { granulomatosa, Inflammatory fibrous hyperplasia, vascular malformation and } \\
\text { hemangioma, neurofibroma, fibrous hyperplasia, lipoma }\end{array}$ \\
\hline Bone pathology & $2(0.95)$ & $2(0.95)$ & $4(1.9)$ & $\begin{array}{l}\text { Central giant cell granuloma, osteoma, fibrous dysplasia, cemento-osseous dys- } \\
\text { plasia, familial gigantiform cementoma }\end{array}$ \\
\hline $\begin{array}{l}\text { Odontogenic cysts } \\
\text { and tumors }\end{array}$ & $10(4.8)$ & $3(1.5)$ & $13(6.3)$ & $\begin{array}{c}\text { Odontogenic myxoma, ameloblastoma, odontogenic keratocyst, lateral peri- } \\
\text { odontal cyst, radicular cyst }\end{array}$ \\
\hline $\begin{array}{l}\text { Dermatologic } \\
\text { diseases }\end{array}$ & $12(5.8)$ & $35(16.8)$ & $47(22.6)$ & Lichen planus, pemphigus \& pemphigoid, erythema multiform \\
\hline $\begin{array}{l}\text { Inflammatory peri- } \\
\text { apical diseases }\end{array}$ & $3(1.4)$ & $1(0.5)$ & $4(1.9)$ & Periapical granuloma, osteomyelitis \\
\hline $\begin{array}{l}\text { Epithelial pathol- } \\
\text { ogy }\end{array}$ & $17(8.2)$ & $27(13)$ & $44(21.2)$ & $\begin{array}{l}\text { Squamous cell carcinoma, epithelial malignant tumor, Spindle cell carcinoma, } \\
\text { verrucous carcinoma, dysplasia, epithelial hyperplasia, hyperkeratosis, squa- } \\
\text { mous papilloma, inverted papilloma, verrucous hyperplasia, verrucous leukopla- } \\
\text { kia }\end{array}$ \\
\hline $\begin{array}{l}\text { Salivary gland } \\
\text { pathology }\end{array}$ & $7(3.35)$ & $2(0.95)$ & $9(4.3)$ & $\begin{array}{l}\text { Mucoepidermoid carcinoma, pleomorphic adenoma, sialadenitis, salivary duct } \\
\text { cyst, mucocele and ranula }\end{array}$ \\
\hline Others & $6(2.9)$ & $9(4.3)$ & $15(7.2)$ & Telangiectasia, traumatic lesions, non-specific inflammation, sinus conditions \\
\hline
\end{tabular}

${ }^{\mathrm{a}}$ Values are presented as No. (\%). 
Pardis S et al.

For four groups of lesions with soft tissue tumors, odontogenic cysts and tumors, epithelial pathology, and dermatologic diseases possessing the highest frequencies, chi-square test was performed. Only for two groups, odontogenic cysts and tumors and dermatologic diseases, there was a significant difference between males and females ( $\mathrm{P}=0.018$ and 0.002 , respectively; chi-square $=5.63$ and 9.47, respectively). For the other two groups, soft tissue tumors and epithelial pathology, the difference was not significant $(P=0.20$ and chi-square $=0.96$ for epithelial pathology, $\mathrm{P}=0.12$ and chi-square $=1.70$ for soft tissue tumors). As this classification failed to show the nature as well as malignant or benign behavior of the lesions, another classification was performed including these variables. The results are shown in Table 3.

Table 3. Frequency of Different Groups of Lesions Based on Their Behaviors ${ }^{a}$

\begin{tabular}{lccc}
\hline Type of Lesion & Male & Female & Total \\
\hline Non-neoplastic & $69(33.3)$ & $84(40.3)$ & $153(73.6)$ \\
Benign neoplastic & $9(4.3)$ & $6(2.9)$ & $(7.2)$ \\
Malignant neoplastic & $10(4.8)$ & $12(5.8)$ & $(10.6)$ \\
Premalignant & $7(3.4)$ & $11(5.3)$ & $(8.7)$ \\
\hline
\end{tabular}

${ }^{\mathrm{a}}$ Values are presented as No. (\%).

There was no significant difference between males and females considering the prevalence of these groups ( $\mathrm{P}>$ $0.05)$. In this classification, premalignant conditions referred to biopsies showed moderate and severe dysplasia, but could not be diagnosed as specific lesions.

\section{Discussion}

Owing to the growing number of elderlies, they are more prone to different types of diseases and lesions. In addition, systemic problems of elderly patients make management of the conditions more complex. As a result, prevention and early detection of life-threatening lesions are of crucial importance.

In spite of the importance of the studied issue, few investigations have been performed in Iran focusing on histopathological features of the lesions. Although clinical examination is essential, it is still not conclusive, especially for malignant and premalignant lesions. In two separate studies performed by Mozafari (8) and Rabiei (9) in Mashhad and Rasht, Iran, respectively, the data were collected by examining both healthy and diseased elderlies clinically; however, we aimed to perform this study on the basis of histopathological diagnosis, which was considered more reliable and conclusive.

The results of this study showed that $17.7 \%$ of biopsies were related to patients of 60 years of age or older. As previously mentioned, SCC was the most common malignant lesion and the third most common lesion (comprising $71.6 \%$ of malignant and $7.6 \%$ of all lesions) among the studied population. In similar studies performed by Carvalho (7) and Correa (4) in Brazil, SCC was the most common type of oral cancer. In another study carried out in England, Warnakulasuriya reported the same findings (11).

Fifty percent of all malignancies were located in lateral border of the tongue; this shows how critical it is for a dentist to find a lesion in this area, even if it does not seem to be a malignant lesion clinically.

The high prevalence of SCC can be attributed to different factors. As SCC is a lesion that does not cause much pain and discomfort, patients may not seek treatment when they first discover the lesion. In addition, elderly people might be more reluctant to refer to a healthcare provider when noticing an abnormal condition in their oral cavities. Another factor might be related to the distance that one should travel from a town or village to refer to a more advanced center for management of his/her lesion. All the mentioned factors might result in developing a premalignant condition into a malignant lesion. OLP was the most frequent lesion observed in our study. In our study, $75 \%$ of patients were female. In a study performed by Shen et al., OLP was more common in females compared with males. In their study, females were twice more inflicted by OLP than males (12). By contrast, Munde et al. reported a higher prevalence of OLP among males $(\mathrm{M}: \mathrm{F}=1.61: 1)(13)$.

Inflammatory fibrous hyperplasia was the second most common lesion in this study (15.8\%). In the study performed by Carvalho et al. inflammatory fibrous hyperplasia comprised $19.1 \%$ of all cases, which was close to our findings (7). In another study performed by Coelho, the frequency of inflammatory fibrous hyperplasia was reported $15 \%$ (14).

Conducting the present study, the researchers faced a number of limitations. For instance, some clinical data, such as systemic condition of the patient, the drugs taken by patients, and locations of the lesions were not mentioned by the referring dentists, so these data could not be used in the reports. Moreover, in some elderly patients, the surgery to take a biopsy was contraindicated because of their systemic conditions. Therefore, a large number of lesions, for which biopsies did not exist, could not be reviewed in this study. On the other hand, since general and oral pathology in some conditions such as salivary gland pathologies overlapped, a great number of biopsies were referred to general pathologists, especially those made by otolaryngologists. As a consequence, salivary gland lesions, despite their high prevalence among the elderly, had been reported for only a small fraction of the cases of this study.

Because of the high frequency of life-threatening oral conditions in elderly populations, it is essential that dentists pay special attention to the most frequent lesions and help enhance the life quality of elderlies by early diagnosis and management of these diseases. 


\section{Acknowledgements}

The authors thank the Vice-Chancellery of Shiraz University of Medical Sciences for supporting this research (Grant \# 6150). This article was based on the thesis by Dr. M. M. Taheri. The authors also thank Dr. M. Vossoughi at the Dental Research Development Center, School of Dentistry, for the statistical analysis and Dr. E. Amalsaleh for improving the use of English in the manuscript.

\section{Authors' Contributions}

Study concept and design: Mohammad Mehdi Fani and Soheil Pardis; acquisition of data: Mohammad Mehdi Taheri; analysis and interpretation of data: Mohammad Mehdi Taheri, Mohammad Mehdi Fani and Soheil Pardis; drafting of the manuscript: Mohammad Mehdi Taheri and Soheil Pardis; critical revision of the manuscript for important intellectual content: Soheil Pardis and Mohammad Mehdi Fani; statistical analysis: Mohammad Mehdi Taheri; administrative, technical, and material support: Mohammad Mehdi Fani and Soheil Pardis; study supervision: Soheil Pardis and Mohammad Mehdi Fani.

\section{Funding/Support}

This study was supported in part by a grant No. 6150 from Shiraz University of Medical Sciences.

\section{References}

1. Berg R, Morgenstern NE. Physiologic changes in the elderly. Dent Clin North Am. 1997;41(4):651-68.
2. Mirzaei M, Ghahfarokhi MS. Demography of elderlies in Iran according to national statistics between 1976 to 2006. Salmand. 2007;2(5):326-31.

3. Scott J, Cheah SB. The prevalence of oral mucosal lesions in the elderly in a surgical biopsy population: a retrospective analysis of 4042 cases. Gerodontology. 1989;8(3):73-8.

4. Correa L, Frigerio ML, Sousa SC, Novelli MD. Oral lesions in elderly population: a biopsy survey using 2250 histopathological records. Gerodontology. 2006;23(1):48-54.

5. Kononen M, Ylipaavalniemi P, Hietanen J, Happonen RP. Oral diseases in the elderly in Finland as judged by biopsy. Compr Gerontol A. 1987;1(3):106-8.

6. Cueto A, Martinez R, Niklander S, Deichler J, Barraza A, Esguep A Prevalence of oral mucosal lesions in an elderly population in the city of Valparaiso, Chile. Gerodontology. 2013;30(3):201-6.

7. Carvalho Mde V, Iglesias DP, do Nascimento GJ, Sobral AP. Epidemiological study of 534 biopsies of oral mucosal lesions in elderly Brazilian patients. Gerodontology. 2011;28(2):111-5.

8. Mozafari PM, Dalirsani Z, Delavarian Z, Amirchaghmaghi M, Shakeri MT, Esfandyari A, et al. Prevalence of oral mucosal lesions in institutionalized elderly people in Mashhad, Northeast Iran. Gerodontology. 2012;29(2):e930-4.

9. Rabiei M, Kasemnezhad E, Masoudi rad H, Shakiba M, Pourkay $\mathrm{H}$. Prevalence of oral and dental disorders in institutionalised elderly people in Rasht, Iran. Gerodontology. 2010;27(3):174-7.

10. Neville BW. Oral and Maxillofacial Pathology:: Saunders/Elsevier; 2009.

11. Warnakulasuriya S. Global epidemiology of oral and oropharyngeal cancer. Oral Oncol. 2009;45(4-5):309-16.

12. Shen ZY, Liu W, Zhu LK, Feng JQ, Tang GY, Zhou ZT. A retrospective clinicopathological study on oral lichen planus and malignant transformation: analysis of 518 cases. Med Oral Patol Oral Cir Bucal. 2012;17(6):e943-7.

13. Munde AD, Karle RR, Wankhede PK, Shaikh SS, Kulkurni M. Demographic and clinical profile of oral lichen planus: A retrospective study. Contemp Clin Dent. 2013;4(2):181-5.

14. Coelho CM, Zucoloto S, Lopes RA. Denture-induced fibrous inflammatory hyperplasia: a retrospective study in a school of dentistry. Int J Prosthodont. 2000;13(2):148-51. 